\title{
Familial Breast Cancer: Clinical Services in the Netherlands
}

Fred H. Menko"

Department of Clinical Genetics, University Hospital Vrije Universiteit, Amsterdam, The Netherlands

\section{EPIDEMIOLOGY: INCIDENCE, AGE AT DIAGNOSIS, FAMILIAL OCCURRENCE}

The incidence of breast cancer in the Netherlands ranks among the highest in Europe. In 19959476 new cases were diagnosed. Age at diagnosis was $<40$ years for $584 \quad(6.2 \%)$ patients. About $10-15 \%$ of cases report a positive family history [1]. An increasing number of patients and family members is referred for genetic counselling, on the basis of young age at diagnosis and/or a positive family history.

\section{ORGANISATION: THE FAMILY CANCER CLINICS}

In the Netherlands eight clinical genetics centers were established in eight university hospitals (Groningen, Utrecht, Amsterdam (VU\&UvA), Leiden, Nijmegen, Rotterdam, Maastricht). Genetic counselling is performed in these centers and, in addition, in two cancer hospitals (Amsterdam, Rotterdam). In "family

\footnotetext{
${ }^{\#}$ Corresponding author: F.H. Menko, MD, PhD, Department of Clinical Genetics, University Hospital Vrije Universiteit, PO Box 7057, 1007 MB Amsterdam, The Netherlands; Tel.: +31 20 4440150; Fax: +31 20 4440769; E-mail: fh.menko.humgen@med.vu.nl
}

cancer clinics" clinical and molecular geneticists, oncologists, and psychosocial workers cooperate using various forms of organisation. The number of registered clinical geneticists in the Netherlands is 62 (01-011999). Twelve clinical geneticists are (mainly) involved in cancer genetics. Genetics nurses, partly involved in cancer genetics, number 20 (April 1999). The number of referrals for cancer at the Amsterdam Family Cancer Clinic of the University Hospital Vrije Universiteit (1994-1997) is presented in Table 1.

\section{CLINICAL EVALUATION: PEDIGREE STUDIES, DNA TESTING, RISK COUNSELLING}

Clinical genetic evaluation includes a pedigree study and may include DNA testing. Cancer risk is based on clinical and DNA-based diagnosis. It is essential that pedigree studies include verification of the family history by review of clinical and histological data [2]. Empiric risk figures for individuals with a positive family history of breast cancer are generally based on the data of Claus et al. [3]. The indications for DNA testing include: 1) age at diagnosis of breast cancer $<35$ years, 2) two first-degree relatives with breast cancer, mean age at diagnosis $<50$ years, 3) three close relatives with breast cancer in two successive generations, at least one of them being $<50$ years at diagnosis. The chance that a causative BRCA1 or BRCA2 mutation is present increases with younger ages at diagnosis, occurrence of bilateral breast cancer and occurrence of ovarian cancer [4]. About 
Table 1

Referrals for cancer, Amsterdam Family Cancer Clinic at the University Hospital Vrije Universiteit, 1994-1997

\begin{tabular}{lcc}
\hline year & $\begin{array}{c}\text { total number of referrals to the department of } \\
\text { clinical genetics }\end{array}$ & $\begin{array}{c}\text { referrals for cancer }(\% \text { of total } \\
\text { number of referrals) }\end{array}$ \\
\hline 1994 & 492 & $114(23.2 \%)$ \\
1995 & 550 & $202(36.7 \%)$ \\
1996 & 679 & $249(36.7 \%)$ \\
1997 & 769 & $306(39.8 \%)$ \\
\hline
\end{tabular}

Table 2

Pathogenic BRCA1 and BRCA2 mutations in breast/ovarian cancer families, the Netherlands, 01-01-1999

\begin{tabular}{lcc}
\hline & number of families with a mutation & number of distinct mutations \\
\hline BRCA1 & 347 & 56 \\
BRCA2 & 70 & 38 \\
total numbers & 417 & 94 \\
\hline
\end{tabular}

$25 \%$ of the Dutch families subjected to DNA testing exhibit a pathogenic BRCA1 or BRCA2 mutation. The number of mutation-positive families and the subdivision of families with BRCA1 and BRCA2 mutations (01-01-1999) is presented in Table 2. Ten different BRCA1/BRCA2 founder and recurrent mutations account for 243 (58\%) of the 417 BRCA1/2 mutation-positive families.

The costs for genetic counselling and DNA testing are covered by health insurance. "Complex genetic counselling" costs $f 2493$ (\$1198, Euro 1131), DNA testing $f 1190$ (\$ 572, Euro 540) (tariffs for Amsterdam per 0101-1999, cost for DNA testing is given per gene: BRCA1 and BRCA2 testing costs $f 2380$ (\$ 1144, Euro 1080)). It takes 3-6 months to perform standard DNA testing on BRCA1 and BRCA2. If a mutation is found in affected family members pre-symptomatic diagnosis takes another two months.

\section{PREVENTION: SCREENING, PROPHYLACTIC SURGERY, FOLLOW-UP}

In the Netherlands population screening for breast cancer consists of two-yearly mammo- graphy from 50-75 years of age. Intensive screening for individuals at increased risk of breast cancer includes monthly breast selfexamination, physical examination by a surgeon every 6 months and yearly mammography. If a woman is a carrier of a pathogenic BRCA1 or BRCA2 mutation, the option of prophylactic surgery will be considered. At the University Hospital Vrije Universiteit in Amsterdam women at increased breast and ovarian cancer risk are investigated periodically at a clinic in which the surgeon, gynaecologist, geneticist and social worker evaluate the situation of the patient. Long-term follow-up of about 100 breast/ovarian cancer families is carried out by the national Foundation for the Detection of Hereditary Tumours (FDHT).

\section{RESEARCH: GENES, PREVENTION, CARE}

National research projects include a) the "GEO-HEBON" project on gene-environment interactions, b) a project on the role of MRI for breast screening. Local projects in Amsterdam include a study of the ATM gene in breast cancer (NKI) and evaluation of the psychosocial aspects of care. 
CONSENSUS: WORKING GROUPS, MEDICAL SOCIETY, HEALTH

\section{COUNCIL}

Consensus is reached by several national working groups: 1) a multidisciplinary national group on breast cancer (HEBON), 2) working groups on cancer genetics for clinical geneticists (WKO) and for molecular geneticists (LOD), 3) a multidisciplinary working group on gynaecological tumours (at the FDHT). Recommendations for DNA testing were drawn up by the Health Council of the Netherlands [5] and the committee on medical ethics of the Dutch Medical Society [6]. A national working group evaluates psychosocial care in cancer genetics.

\section{Acknowledgement}

F.B.L. Hogervorst, the Netherlands Cancer Institute, Amsterdam, for data of Table 2.

\section{References}

[1] Anton-Culver, et al., Genet. Epidemiol. 13, (1996) 193-205.

[2] Douglas, et al., J. Med. Genet. 36, (1999) 309312.

[3] Claus, et al., Cancer 73, (1994) 643-651.

[4] Ligtenberg, et al., Br. J. Cancer 79, (1999) 1475-1478.

[5] Health Council of the Netherlands, Committee on DNA-diagnostics, Rijswijk, publication 11, (1998).

[6] Dutch Medical Society, Committee on Medical Ethics, Doctors and genes. Use of genetic knowledge in medical practice. Utrecht, 1997. 


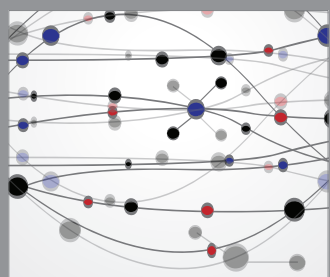

The Scientific World Journal
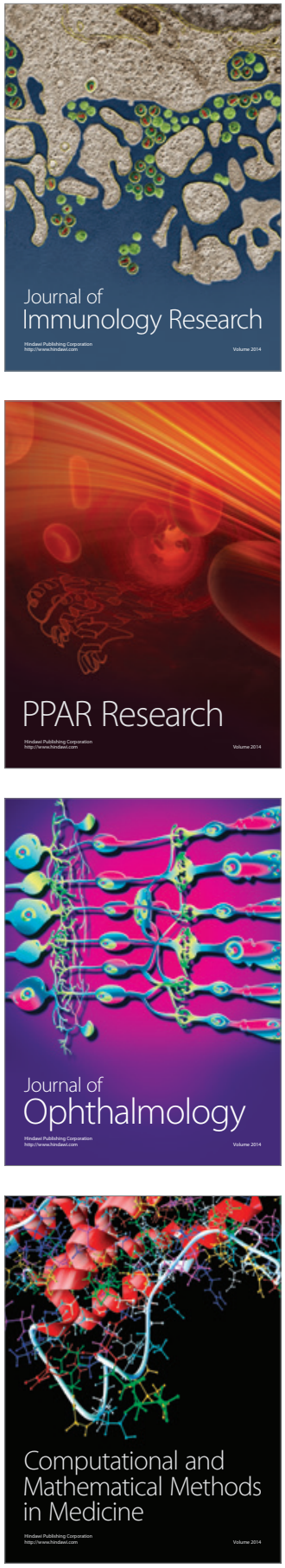

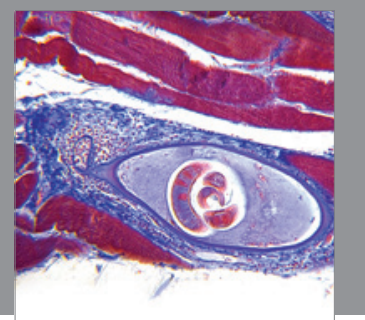

Gastroenterology

Research and Practice
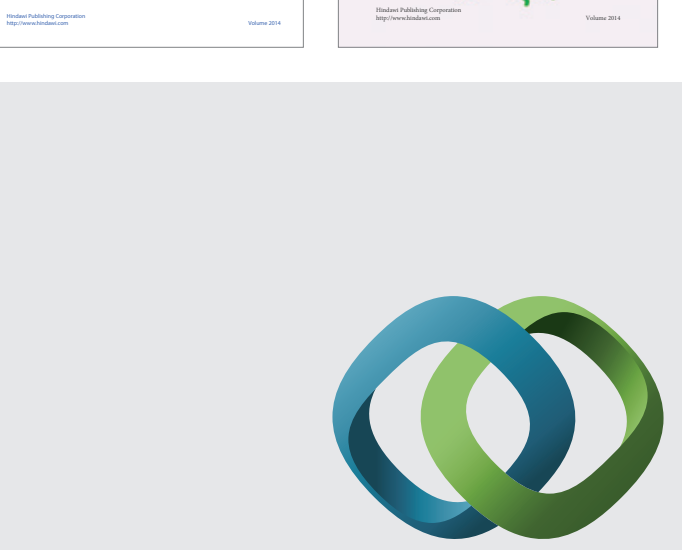

\section{Hindawi}

Submit your manuscripts at

http://www.hindawi.com
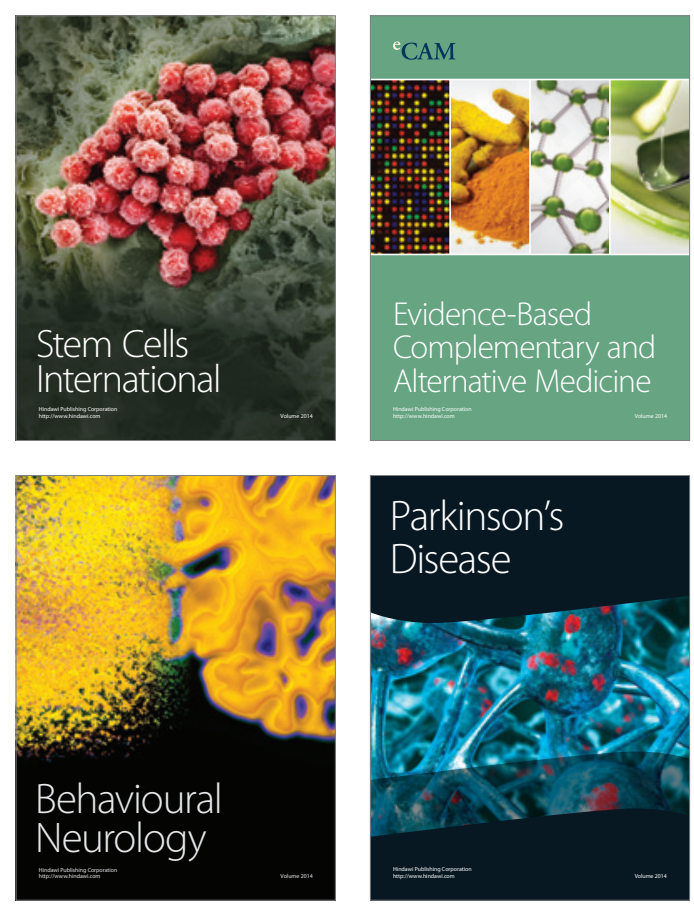

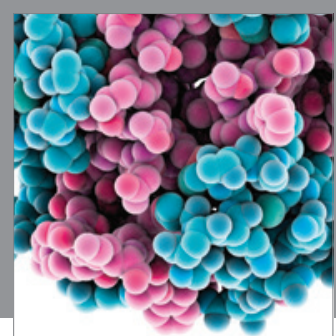

Journal of
Diabetes Research

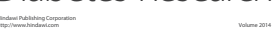

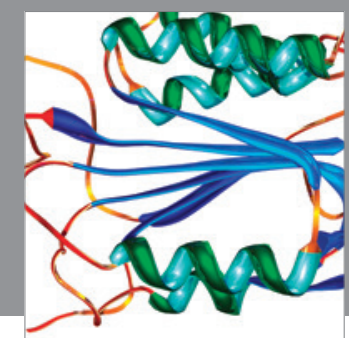

Disease Markers
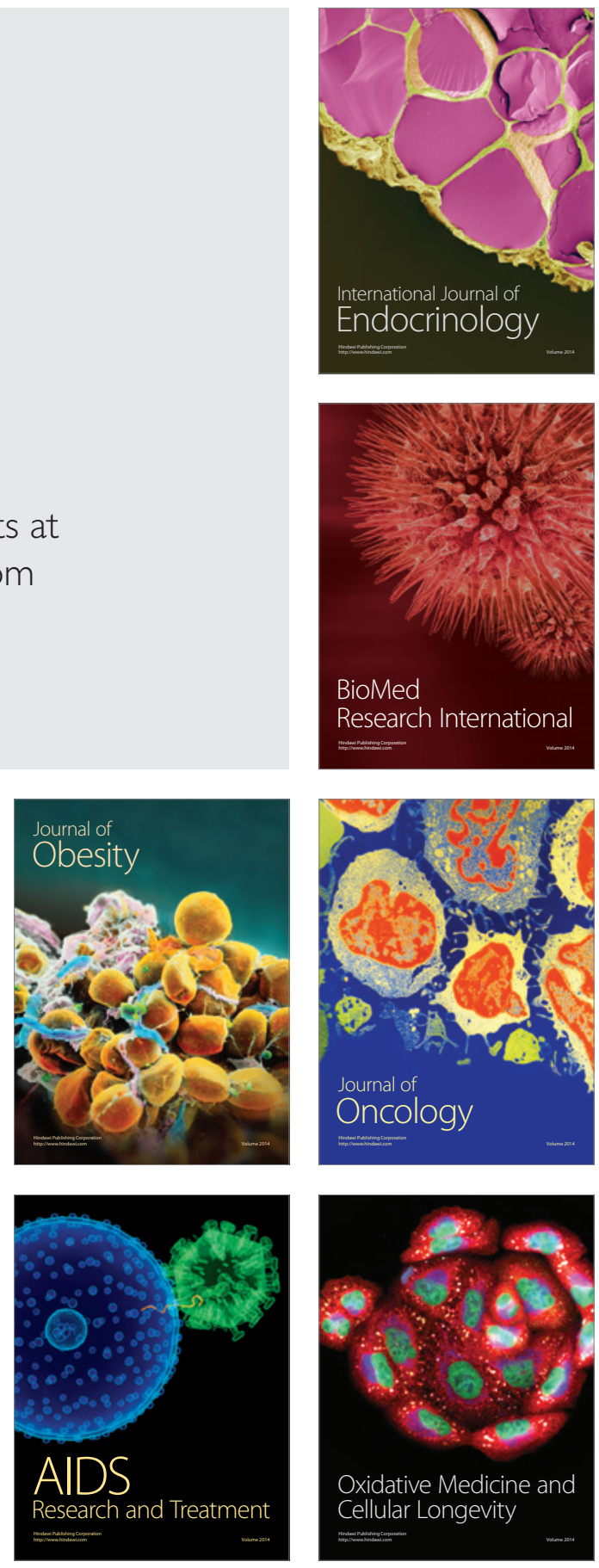